\title{
Os Saberes dos Professores e o Ensino da Radiologia no Curso de Graduação em Medicina da UFRJ: Experiência de Vida ou um "Simples" Exercício da Docência?"
}

\author{
Professors' Knowledge and the Teaching of \\ Radiology at the Medical School of the \\ Federal University in Rio de Janeiro (UFRJ): \\ a Life Experiência, or Merely a Teaching
} Exercise?

\author{
Maria de Fátima do (O' Corrĉa Ciomes \\ Evandro Guimarảes de Sousa \\ Hilton Augusto Koch ${ }^{3}$
}

PALAVRAS-CHAVE

- Educação Médica;

- Radiologia - educação;

- Doccntes de Medicina;

- Conhecimento.

KEY-WIORDS:

- Education, Medical;

- Radiology-education;

- Facultr, Mfedical;

- Knowledgc.

Recebido em: 24/03/2004

Reencaminhado cm: 11/08/2004

Reencaminhado cm: (19/09/2004

Aprovado cm: 30/(0)/2004

\section{RESUMO}

Este trabalho é um rehalo da experiência que o docente do Departamento de Radjologia da Faculdade de Medicina da Lniversidade Federal do R'io de Jankiro e do Hospital Liniversitário (Kementino Fraga Filho tem com o ensino da disciplina. A partir de entrevistas semi-estruturadas junto aos vinte quatro docentes, através das quais foram coletados os dados que permitiram classificar os diferentes sabercs acumulados pello corpo docente na (IFK). Conchiu-se com a pesquisa quc, os saberes dos professores sempre implicam em uma relaçăo social, seja ela com os seus alunos, seus pares, sua familia e com lodos que trabalham e convivem direta ou indirctanente no seu colidiano de ensino.

\begin{abstract}
This study reports on the teaching experience of faculty members at the Department of Radiokgy. Mectical School, Federal Lniversity in Rio de faneiro and the Clementino Fraga Filho Liniversity Hospital. A semi-structured interview with 24 professors allowed classifying the different forms of knowledge accumulated by the: faculty at the [IRR. The conclusion was that the professors' knontedge atways involved a social relationship, whether with students, peers, family, and all those who work and have direct or indirect contact with them in their daily teaching practice.
\end{abstract}

-Trabalho desenvolvido no Deparfamento de Radiologin da Faculdnde ae Medicina da Unitucrsidnde Federal do Rio de Janeiro. ${ }^{5}$ Mestre en: Ciéncias. Faculdade de Medicina, Universidade Federal do Rio de Jmeiro, Rio de Jnueiro, Brasil.

${ }^{2}$ Doutor em Radiologia, Faculdude de Medicina, Universidacte Federal do Rio de Janeiro, Rio de fanciro, Brasil.

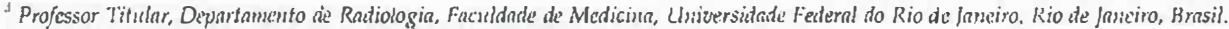




\section{INTRODUÇÃO}

A adoção de novas técnicas de ensino e a utilização de modernos recursos audiovisuais sempre constituiram prioridades do Departamento de Radiologia da Faculdade de Medicina da Universidade Federal do Rio de Janeiro, no sentido de assegurar a qualidade do ensino desta especialidade para os alunos dos cursos de graduação e de pós-graduação. Portanto, várias pesquisas foram desenvolvidas naquele Departamento relacionadas com o ensino desta especialidade.

O primeiro trabalho relacionado com o ensino da Radiologia foi realizado por $\mathrm{Koch}^{1}$ (1987) que avaliou o desenvolvimento do processo ensino-aprendizagem na disciplina de Radiologia oferecida por 76 escolas de Medicina no Brasil. A pesquisa concluiu que a metodologia de ensino era deficiente, incluindo a ausência de material didático e de equipamento radiológico. Que tanto eram deficientes os recursos humanos quanto os equipamentos destinados ao ensino da Radiologia. Koch ${ }^{1}$ inclusive recomendou que ao final do curso de graduação, o professor deveria capacitar o seu aluno a identificar os exames radiológicos pedidos, solicitar exames de diagnóstico por imagem adequados para o tipo de problema de saúde apresentado pelo paciente, conhecer o preparo do cliente para os diversos tipos de exame e correlacionar estes exames com as informaçōes obtidas pela anamnese, exame físico e outros testes complementares realizados.

Tonomura², em 1989, aconselhou que as aulas de Radiologia deveriam ser ministradas por médicos radiologistas, como disciplina obrigatória, utilizando procedimentos de ensino que permitissem uma maior participação do aluno, quando o professor assumiria a função de coordenador das atividades programadas, evitando o excesso de aulas expositivas.

Em 1992, Paschoal ${ }^{3}$ analisou o ensino da Radiologia que era oferecido nos Programas Curriculares Interdepartamentais que utilizavam o modelo de ensino interdisciplinar tendo por objetivo integrar conhecimentos em Anatomia Patológica, Clínica Médica e Radiologia. Este modelo de ensino buscava cultivar no aluno a capacidade de resolução de problemas, baseado numa visão de que o homem precisa ser atendido nos seus aspectos bio-psico-sociais. Aquela metodologia, na época, teria também o objetivo de evitar que o conteúdo não se tornasse repetitivo e que fossem abordados de maneira global e integrados nestas três áreas citadas.

Em meados de 1995, Paschoal', iniciou uma nova metodologia baseada nos postulados de Skiner 5 , sugerindo que o professor oferecesse o conteúdo em pequenas etapas, possibilitando uma participação mais ativa dos alunos. Porque só quem exercita, fala ou coloca em prática o que aprende, tem a chance de externar o que aprendeu. Com esse método, os exer- cícios são aplicados com correção imediata, lembrando que o aluno possui ritmo próprio de aprendizagem que deve ser respeitado, portanto, é necessário repetir o mesmo assunto de modos diferentes.

A Radiologia não é uma disciplina ministrada isoladamente nos Programas Curriculares Interdepartamentais de Propedêutica Clínica e Medicina Interna I. A cada dois semestres (respectivamente no quarto e no quinto período da Graduação), a Faculdade de Medicina da UFRJ, matricula 96 alunos por período.

A metodologia do ensino de Radiologia na Graduação em Medicina da UFRJ está baseada em resolução de problemas que segundo Paschoal't, é a técnica de ensino mais adequada para o desenvolvimento das aulas práticas e subseqüentemente, uma sistematização dos conteúdos.

O programa de Propedêutica é desenvolvido em 20 semanas com aulas de 2 horas de duração num total de $40 \mathrm{~h} /$ aula. A duração do programa de Medicina Interna I é de 20 semanas. Porém, como a turma é dividida em 2 duas partes, efetivamente, o curso possui 10 semanas em Radiologia e 10 semanas em Medicina Nuclear, ambas com aulas de 2 horas de duração num total de 20h/aula em Radiodiagnóstico e 20h / aula em Medicina Nuclear.

São quatro professores que se revezam semanalmente nos cursos de Radiologia e três, na Medicina Nuclear. Os instrumentos de avaliação do ensino são compostos de prova escrita e prova prática permitindo aos alunos que, uma vez colocados diante de práticas do cotidiano do Radiologista, demonstrem suas habilidades e competências ao se depararem com situaçōes-problema que thes são apresentadas a título de verificação de aprendizagem.

Trabalhos como os de $\mathrm{Koch}^{6}$ e colaboradores culminaram na edição do livro: "A Radiologia na formação do Médico Geral". Também a pesquisa de Geraldeli? ${ }^{7}$ destacou a produção de material instrucional para o ensino da especialidade por meio de imagens digitalizadas assim como o trabalho de Silva ${ }^{8}$ que estudou os achados videofluoroscópicos da dinâmica da deglutição.

Sabe-se que na maioria das vezes, o docente em Medicina é contratado de acordo com o seu desempenho como profissional ou no seu destaque como pesquisador. Ao contrário de outras áreas do conhecimento, como nas ciências humanas, não é exigida a formação do médico como professor durante a sua graduação ou especialização. Além do que, em algumas instituiçōes, para a função de ensinar é conferido um status inferior ao da pesquisa, com incentivos maiores para progressão dessa carreira, do que propriamente para o exercício da docência. 
QUADRO I

Os saberes dos professores

\begin{tabular}{|c|c|c|}
\hline Sabere's dos profe'ssores & Fontes socinis de aquisigño & Motos de inlegraçño no traballho docente? \\
\hline Saberes pessoais dos professores & $\begin{array}{l}\text { Familia, ambiente de vida, a educação no } \\
\text { sentido lato, etc. }\end{array}$ & $\begin{array}{l}\text { P’ela história de vida e pela socializaçāo } \\
\text { primária }\end{array}$ \\
\hline $\begin{array}{l}\text { Saberes provenientes da formação escolar } \\
\text { anterior }\end{array}$ & $\begin{array}{l}\text { A escola primária e secundária, os estudos } \\
\text { pós-secundários não especializados, etc. }\end{array}$ & $\begin{array}{l}\text { Pela formação e pela socializaçāo } \\
\text { pré-profissionais }\end{array}$ \\
\hline $\begin{array}{l}\text { Saberes provenientes da formaçāo } \\
\text { profissional para o magistério }\end{array}$ & $\begin{array}{l}\text { Os estabclecimentos de formaçāo de } \\
\text { professores, os estágios, os cursos de } \\
\text { reciclagem, etc. }\end{array}$ & $\begin{array}{l}\text { Pela formação e pela socialização } \\
\text { profissionais nas instituiçōes de formação de } \\
\text { professores }\end{array}$ \\
\hline $\begin{array}{l}\text { Saberes provenientes dos programas e livros } \\
\text { didáticos usados no trabalho }\end{array}$ & $\begin{array}{l}\text { Na utilização das "ferramentas" dos } \\
\text { professores: programas, livros didáticos, } \\
\text { cadernos de exercicios, fichas, etc. }\end{array}$ & $\begin{array}{l}\text { P'ela utilização das "ferramentas" de trabalho, } \\
\text { sua adaptação às tarefas }\end{array}$ \\
\hline $\begin{array}{l}\text { Saberes provenientes de sua própria } \\
\text { experiência na profissão, na sala de aula e na } \\
\text { escola }\end{array}$ & $\begin{array}{l}\text { A prática do ofício na escola e na sala de aula, } \\
\text { a experiência dos pares, etc. }\end{array}$ & $\begin{array}{l}\text { Pela prática do trabalho e pela socializaçāo } \\
\text { profissional }\end{array}$ \\
\hline
\end{tabular}

Sem o preparo para atuar como professor, o médico constrói sua própria didática tendo por base os modelos que conheceu quando aluno, através da sua experiência profissional e de vida, selecionando os procedimentos que julga mais adequados para as suas aulas. Em virtude da forma como conduz o ensino, nem sempre procura estabelecer uma reflexão sobre o seu desempenho individual, nem com o dos outros professores que atuam na mesma disciplina ou que lecionam no mesmo curso".

Tardif e Raymond ${ }^{10}$ classificaram os saberes do professores de acordo com os locais onde foram adquiridos e as maneiras de integração no seu traballho. Saberes que, em muitas das vezes, não são percebidos pelos próprios docentes.

Incontri" propōe para uma educação integral, que é preciso haver equilíbrio entre a inteligência e o sentimento, entre o biológico e o psíquico, entre o social e o espiritual, guardando as devidas atenções para outros elementos culturais, sociais, estéticos e éticos na busca de um homem completo. Portanto, os professores de Medicina devem estar cientes e procurar incentivar os seus alunos a se preocuparem também com tais questões.

Mas qual seria a participação dos docentes do Departamento de Radiologia frente a estas inovações do ensino? Quais saberes dos professores estariam envolvidos no exercício diário da docência e como seria o preparo desses médicos para exercer o magistério?

No scntido de elucidar estas questões, desenvolveu-se esta pesquisa com o objetivo de verificar qual a articulação entre os saberes dos docentes e o ensino da R.ıdiologia na FM/UFRJ.

\section{OBJETIVO}

Esta pesquisa teve como objetivo demonstrar como os docentes conduzem o ensino da Radiologia no curso de me- dicina da UFRJ. Relatar o que os professores entendem como caminhos c obstáculos para que o processo ensino-aprendizagem se desenvolva, assim como classificar os seus saberes $\mathrm{e}$ sua aplicabilidade, no sentido de contribuir para a formação em Radiologia dos futuros médicos.

\section{MÉTODO}

O cenário desta pesquisa é o Departamento de Radiologia da Faculdade de Medicina da Universidade Federal do Rio de Janeiro, seus atores são os 24 docentes lotados neste Departamento.

Optou-se pela realização de uma pesquisa qualitativa, porque esta permite ao pesquisador uma maior criatividade e flexibilidade na coleta e na análise dos dados. Esta modalidade de pesquisa permite a identificação de conceitos e variáveis relevantes de situações que, também, podem ser estudadas quantitativamente. A pesquisa qualitativa é muito utilizada para o estudo de questões difíceis de quantificar, tais como: os sentimentos, as motivações, crenças e atitudes individuais ${ }^{13}$.

\section{RESULTADOS}

Dos vinte e quatro docentes entrevistados, tre\%e pertencem ao sexo masculino e onze ao feminino. Destes, treze são Doutores, sete são Mestres, três Especialistas e um é graduado.

Observou-se que da totalidade docente, dois são Titulares, dez são Adjuntos, onze são Assistentes e um é Auxiliar de ensino.

Somente após um estudo criterioso totalizando de\%esseis horas de entrevistas gravadas e de uma análise discursiva das mesmas, é que foi possível localizar os diversos saberes dos docentes e o que eles representam para o ensino da Radiologia do curso de Medicina da UFRJ. 
Classificou-se os saberes dos professores do Departamento de Radiologia da UFRJ, com base nas recomendaçōes de Tardif e Raymond ${ }^{10}$.

Quanto ao uso e às atribuiçōes dos professores no que diz respeito a ensinar Radiologia e formar futuros médicos, o docente insere o acadêmico no contexto do que pode representar para ele desenvolver um trabalho científico, prestar assistência médica embora a pesquisa tenha localizado variadas formas sobre como desenvolvem e como administram o cotidiano de ensino no Departamento. No decorrer das entrevistas, os docentes abordaram naturalmente questōes da Bioética, da Teoria da Comunicação na Educaçāo Médica e o que é vivenciado na relaçāo educandos e educadores, correlacionando sempre o ensino da Radiologia com as dificuldades que encontram para suas realizaçōes profissionais, demonstrando assim que esses assuntos se interligam na prática do dia a dia do professor e como recomenda Schramm ${ }^{13}$.

Com base no roteiro das entrevistas (Anexo I), o docente, ao ser provocado a pensar e a declarar sobre assuntos que estāo diretamente ligados ao seu cotidiano profissional, a pesquisa ouviu:

\section{Sobre a Trajetória de Vida dos Docentes:}

“...O momento mais importante da minha vida como docente, foi no Serviço do Professor Clementino Fraga Filho, na Santa Casa de Misericórdia, na Enfermaria vinte, onde nós tínhamos pequenos grupos e nós ensinávamos Semiologia...O contato com estes alunos era direto e ele persistia nāo só na parte da manhā como por algumas ocasiōes, na parte da tarde onde nós reforçávamos essas aulas...Não sei se esse tipo de aula continua na Universidade. O professor não tem só a necessidade de ensinar a parte científica. $O$ professor também serve como modelo para seus alunos. Ele é uma bússola... Baseado nāo só naquilo que ele aprendeu mas pelo poder daquele professor. Eu posso dizer que talvez o fato mais importante foi que eu tive neste pequeno grupo, um aluno que hoje transformou-se em um brilhante professor da nossa Universidade, inclusive um excelente Pediatra da parte digestiva....Recentemente eu tive a necessidade de precisar de seus serviços e por ocasiāo de ter nascido duas netinhas prematuras e que o professor as atendeu salvando a vida de uma delas. E ele disse o seguinte: que ele nāo poderia esquecer das aulas que eu tinha dado para ele no Hospital Getúlio Vargas onde eu levava meus alunos...Ele diz que nāo foi só exatamente o ensino, mas foi a bússola que eu dei para ele...Ele lembrou que eu levava eles para o meu plantāo do Hospital Cetúlio Vargas. Quer dizer, o que marcou mais a vida dele, não foi eu como professor da parte curricular, o docente dele, mas o que marcou foi eu ter levado e dado a chance a ele de levá-lo para um hospital..."

Neste sentido a pesquisa ouviu um depoimento revelando a consciência que o docente tem que o seu saber é proveniente da sua historia de vida e que a sua experiência é muito importante para o desempenho de sua função declarando: "... Se você puder fazer com que o teu aluno, com que o teu Residente, com a pessoa que você convive mais amiúde, passar a tua informação, ou melhor a tua experiência de vida, nāo é? Agora você tem que passar aquilo que ele pode entender e o que ele pode metabolizar dentro da cabeça dele."

\section{Sobre as Condiçōes de Trabalho do Docente:}

Alguns depoimentos são contraditórios em alguns casos porque ao mesmo tempo em que o docente se revela orgulhoso por trabalhar na instituição, não suporta a decadência da qualidade dos serviços prestados pelo Hospital Universitário à sua comunidade e declara à pesquisa: "... Sim, me orgulho. Para mim é um privilégio participar das atividades docentes junto aos alunos. É um motivo de grande orgulho para mim, fazer parte do grupo de treinamento de Residentes ... O nosso problema atual é a crise do Hospital. O que gera aqui no meu serviço é a falta de materiais para a realizaçāo dos procedimentos. Isto gera muito, muito desapontamento. Ter que desmarcar exame. É muito desagradável você ter que quebrar a expectativa das pessoas com exames marcados. Falta material, como está acontecendo hoje, como você mesmo pode observar. Este é o maior problema atual. A falta de material para a realizaçāo de procedimentos programados."

"...Todos nós sofremos... (referindo-se o docente, à discriminação salarial, a qual julga que sofre) A salarial do tipo a gente trabalhando na greve sem receber. Trabalhando direto. Você é cobrado por de repente deixar de dar laudo. Eu venho aqui fora de hora numa quinta-feira por exemplo. O médico, cuja obrigação era de estar aqui, tinha faltado. Eu vim fora de hora fazer uma embolizaçāo porque o doente estava sangrando e isso nāo é reconhecido. Não é levado em conta".

Ficou bastante evidenciado com a pesquisa, as controvérsias que os docentes enfrentam com a questāo da remuneraçāo. E, mais uma vez destacamos essa evidência ao ouvir:

"... Eu ganho como docente, eu não ganho para atender. Essa é uma questāo. Atender o que?... Existe agora um sem número de universidades privadas que na realidade são empresas para dar lucro. Eu não consigo ver Medicina dando lucro. Se você pensar em saúde e educação em coisa que dá lucro, é um negócio preocupante. Eu não sei que tipo de informaçāo você pode dar às pessoas que sāo formadas para isso... Será que daqui a pouco os médicos vāo ter de usar no jaleco: MÉDICO. COCA-COLA, NIKE?" 


\section{DISCUSSÃO}

As variadas origens dos saberes dos professores foram localizadas e devidamente classificadas, formando uma multiplicidade de fatores que independem do ofício de ensinar. Esta diversidade de saberes, que é "exterior" 10 àquele ofício, pode ser encontrada em vários setores sociais, tais como: na família do professor, na escola que o formou, na sua cultura pessoal ou até mesmo na universidade. O rastreamento das idéias contidas neste trabalho, buscou sintetizar as leituras e as análises feitas nas áreas afins em questão, porque são inegáveis os esforços epistemológicos concentrados na P'sicologia, na Educação, na Ética e na Antropologia Cultural que carecem de informar ao médico em formação a importância do conhecimento nestas áreas, conforme as recomendações contidas nas Diretrizes Curriculares Nacionais para o Curso de Graduação em Medicina ${ }^{14}$.

Conforme o Quadro I de Tardif e Raymond ${ }^{10}$ e a reclassificação dos saberes dos docentes desta pesquisa, foi possível localizar diferentes fontes. Saberes de professores que entendem que está na família sua base maior de formação. As fontes que demonstraram que o conhecimento e o reconhecimento de seus saberes podem estar diretamente ligados ao tempo de atuação que ele acumula na Universidade. Que podem implicar também esses saberes, em uma relação social, assim como a troca dos mesmos com os grupos, instâncias e indivíduos que us produzcm c com os quais eles se relacionam e que muitas vezes independem da sua vontade.

O que existe $e$ foi destacado pela pesquisa, é que há ainda uma distância entre o que o docente sabe que precisa ser feito para qualificar o seu traballho de professor, e o que efetivamente pode ser feito em termos de recursos materiais oferecidos tanto pela Universidade quanto pelo Hospital Universitário Clementino Fraga Filho que é, e precisa prosseguir funcionando como um hospital-escola.

Mas como compartilhar tantos saberes em tantas áreas e alcançar um ensino ideal? Saberes que precisam estar presentes, tanto no médico que ensina, quanto naquele que ensina e não deixa de ser médico au ensinar. Quem constrói as normas que regem a humanidade são os mesmos que teoricamente vislumbram o progresso. Esse mesmo progresso depende de quem constrói. E é aí que a proposta da transdisciplinaridade, que também é indiretamente a proposta do ensino médico, porque transcende às disciplinas convencionais do currículo e que estão embutidas e acumuladas nos saberes e nas condutas dos docentes. Portanto, o que recomendam Koch ${ }^{1}$, Tonomura ${ }^{2}$, Paschoal ${ }^{3 e 4}$, Skiner ${ }^{5}$ e Incontri ${ }^{10}$, se complementam e se interligam neste trabalho. Porque cada um desses autores, embora atuando em áreas distintas, o que defendem veementemente em suas pesquisas, são as propostas que acabam transcendendo a um tempo real, porque buscam um mesmo objetivo. O de formar médicos, formar sobretudo homens para um mundo melhor do que este que estamos vendo hoje.

Ensinar Radiologia neste sentido, passa a ser um desafio instigante, sobretudo quando é necessário seguir as normas básicas contidas nas Diretrizes Curriculares Nacionais do Curso de Graduação em Medicina15. Nesse documento está definido o que a sociedade brasileira espera, tanto dos médicos que a Universidade qualifica, quanto dos professores que formam futuros médicos. De acordo com o Artigo 4, para formar um bom e consciente médico, o professor precisa conhecer muito bem e ensinar para o seu aluno, conceitos básicos de: comunicação e liderança, tomada de decisões, atenção à saúde, atendimento e gerenciamento e por fim, ensinar o que representa uma Educação Permanente para o futuro médico. É difícil fazer tanto o docente quanto o aluno, entenderem essa proposta que não é a nossa, mas sim uma proposta mundial quando o assunto é Educação Médica? Sim, mas não se busca facilidades quando se trabalha com pesquisa.

Com base nas entrevistas, buscou-se responder à três perguntas básicas: Quando se ensina, para quê se ensina? Quando se ensina, para quem se ensina? Quando se ensina, o que é necessário saber para se ensinar? Desta forma, foi feito um trabalho classifica tório dos saberes dos docentes. Foram localizados os saberes provenientes da formação de cada um, objetivando o seu exercício para o magistério. Saberes que determinam o perfil do docente em momentos eminentemente pedagógicos que passam despercebidos por ele, mas que tornam-se inesqueciveis. Saberes provenientes da sua própria experiência na profissão de médico, delineando um perfil que não só valoriza, como é reconhecido no seu discurso e na sua prática pedagógica, uma indissociabilidade da Educaçãocomo um todo do ensino médico, como revelou textualmente um determinado docente ao dizer: "...O professor não tem só a necessidade de ensinar a parte científica. O professor também serve como um modelo para seus alunos". Perfil de docente que exercitando o seu saber pessoal como professor, não se dá conta de que esse saber pode certamente ter sido originado na família, em um ambiente de vida social qualquer, na educação no seu sentido lato, ou na prática do seu ofício e na experiência com seus pares, ou tudo isso conjugado entre si: "...O que eu me lembro é que eu tinha um boletim ...naquela época era diferente. Nós éramos professores. Era ali que a gente podia aprimorar a função docente ... Talvez tenha sido a melhor coisa que a Universidade ofereceu. Era um curso didático-pedagógico. Nós éramos trinta alunos e uma coisa maravilhosa!" Foi um curso completo com aulas de Pedagogia, Filosofia e Ética... Com uma professora ... era ... Riva! Riva e Ester. Eram duas irmās." 
Docente com mais tempo de dedicação e serviços prestados à universidade, declarou que é muito difícil conciliar o ensino com a assistência médica e com a pesquisa, revelando a dificuldade que é conciliar esse trinômio. Constatou-se através das entrevistas, que a prática da docência se confunde muito com a da pesquisa e da assistência médica, gerando um certo desconforto, porque passa pelas questōes cruciais do relacionamento humano. Passa pelas questões das vaidades. Pelas questōes das hierarquias "...Nem de Mestrado nem de Doutorado. Não gostaria de defender nenhuma tese...Não é uma coisa real, sabe? É somente para cumprir carga. É praticamente impossivel fazer alguma coisa nova...Tudo que foi imaginado já foi feito. Em teoria é bonito mas na prática? Mudar isso é dificil...A gente sempre foi ligado ao Departamento de Clínica. Não adianta começar ... Nossa voz nāo é tão forte ... A gente não dá um curso de Radiologia separado da Clinica".

Sentimentos antagônicos, tais como: as queixas e paralelamente o prazer que alguns docentes revelam experimentar no cotidiano de ensino no Departamento, fizeram com que a pesquisa fosse buscar em Menezes ${ }^{15}$, como isso se processa nas mentes de quem precisa estar todo tempo teoricamente equilibrado para ensinar Radiologia. Segundo Menezes ${ }^{16}$, o prazer quando sentido e revelado textualmente por parte dos docentes no exercicio das suas funçōes, foi um fato que assumiu muita importância para a pesquisa. Porque se o que um docente faz com responsabilidade lhe dá prazer, melhor resultado conseqüientemente trará em forma de beneficio para o aluno que receberá em dobro um docente mais responsável e gratificado no seu cotidiano pedagógico.

Entretanto, quando nem todos sentem prazer em fazer aquilo que realizam, as queixas aparecem naturalmente, como ficou evidente no discurso do docente. Em contrapartida a estes fatos, muitas vezes a irritação, segundo Menezes ${ }^{15}$, é um estado em que muitos de nús nos encontramos quando temos queixas a fazer. Representa à reação a uma crença de que tudo devia ser do jeito que queremos. Quando constatamos que a vida ou os outros, não atendem à essas nossas conviç̧ões, nos irritamos indignados. Muitas vezes impacientes com aqueles que nāo pensam comonós, chegamos a afirmar: "NNāo agüento a burrice de fulano!", "Quantas vezes eu vou ter que explicar para você?", "Como você é lerdo!", "Pobreza não é comigo!" Irritamo-nos nessas situaçōes porque esperamos que tudo funcione a partir dos nossos parâmetros. Quando se trata de ensinar medicina então, julga-se que se está ensinando para os melhores exemplares da espécie humana, como se não existisse mais outra profissāo também capaz de aprender o que quer que seja. Declaraçōes do tipo: "Os alunos que estudam na UFRJ são os que têm um pontinho a mais no cérebro". O que seria o mesmo que afirmar, que todos aqueles que não estudam na UFRJ, nāo teriam condiçōes intelectuais para aprender Radiologia.

Para Osório ${ }^{16}$, é recomendado que se tenha uma especial a tenção e que seja também levantada a discussão para o tema de que os médicos, os dentistas, os enfermeiros, os fisioterapeutas, os psicólogos, os professores, os assistentes sociais cuidem da manutenção da saúde mental, intelectual e física das pessoas, mas que nāo seja negligenciado também a seguinte questāo: E quem cuida dos cuidadores? Quem represa a sobrecarga emocional desses "cuidadores"? Sim, porque, se as normas atuais que recomendam e determinam o que um aluno de medicina precisa aprender recomendando que ele transite por tantas áreas do conhecimento, podem auxiliar na formaçāo do médico, isso só, nāo vai garantir o domínio total de saberes. Porque o ser humano tem um limite de armazenamento de conhecimento. Porém, o fato de saber que é preciso sobretudo se ter a uniāo dessas áreas e que essa proposta só vai somar e aperfeiçoar ainda mais a formaçāo do futuro médico, já representa um grande avanço para um tipo de ensino que não pode, nem deve se dar ao luxo de ficar estático.

Realizar um trabalho de diagnóstico qualitativo como este, praticamente obriga por parte de quem pesquisa, percorrer um caminho que possibilitou como nesta pesquisa, reunir um farto material colhido através das entrevistas. A análise exaustiva dos discursos dos professures feita à partir dos depoimentos, encontrou a essência dos fenômenos observados na dinâmica do Departamento. O pensamento e a análise daqueles fenômenos puderam ser compreendidos sempre considerando que, o pensamento fenomenológico traz para o campo do estudo da sociedade, o mundo da vida cotidiana onde o homem se situa com suas angústias e preocupações. Sabe-se que é impossivel hoje, através de estudos é trabalhos realizados por sociólogos, psicólogos e igualmente respeitados educadores, isolar o desempenho de um profissional em exercicio, sem considerar seu meio social, suas condições econômicas, familiares e sentimentais, que permeiam o universo de emoçōes que representa a vida de alguém que visa a saúde. Mas todos esses obstáculos precisam ser enfrentados por profissionais que carecem de entender e se despojarem de sentimentos egocêntricos que em nada contribuem para uma sociedade melhor e mais preparada para enfrentar os desafios do cotidiano de ensino de um hospital-escola como Hospital Universitário Clementino Fraga Filho.

\section{CONCLUSÕES}

Os saberes dos professores sāo existenciais e estão diretamente ligados às suas vidas e nāo apenas ao momento $\mathrm{em}$ que ensinam no Departamento. Seus estilos de vida influen- 
ciam a mudança de comportamento do radiologista frente a determinadas situaçōes encontradas no excrcício do magistério e que muitas vezes são agravadas pelo fato de eles não terem uma formação pedagógica.

O uso dos saberes dos professores vai sempre implicar em uma relação social, assim como a troca daqueles saberes com os grupos, instâncias e individuos que os produzem e com os quais eles se relacionam, porque muitas vezes independem de suas vontades. Os fundamentos que regem e estruturam o ensino no Departamento, sejam eles em que bases foram estruturados, são essencialmente sociais na medida em que os saberes profissionais são plurais, oriundos de fontes diversas (família, escola, universidade, etc...), adquiridos em tempos sociais diferentes. O tempo da infância, da escola, da sua formação, ligados ou não ao seu desempenho profissional como um todo ou à sua passagem pela universidade, assumem um peso considerável quando se entende que esses saberes são saberes em movimento e que vão passando de geração após geração.

A forma como conduzem o ensino da Radiologia no Departamento ficou bem clara nos depoimentos dos docentes. Eles ensinam Radiologia aos seus alunos e se orgulham por isso, entretanto algumas vezes sem perceberem claramentc que o que fazem é ensinar, mesmo quando estão fora do ambiente formal de ensino. Utilizando-se de metodologia própria, os docentes ainda assim, dizem que não ensinam e que estão apenas prestando um serviço de assistência, quando na realidade, estão ensinando, só que fora da sala de aula. Isto ficou explícito nos seus discursos. Ensinam o que sabem e como aprenderam com seus pais, seus mestres, seus colegas, scus pacientes. A influência do tempo de atuação que o docente tem dedicado a Universidade valoriza a sua prática pedagógica. Os saberes que os docentes revelam possuir e a relação desses saberes com a sua formação adquirida fora da Universidade, demonstram que a insatisfação revelada por parte de alguns professores, o ressentimento e o orgulho são sentimentos contraditórios tais como: ora a auto-estima do docente está em alta, ora está em baixa, criando barreiras emocionais que precisam ser cnfrentadas. Elas são diversas e impossibilitam ter um profissional equilibrado e feliz no exercício de uma função que requer sempre, e na melhor das hipóteses, alguém contente com o que faz. Entretanto o baixo salário foi apontado como um dos maiores obstáculos para um desempenho mais prazeroso da função daquele que ensina, pesquisa e presta assistência médica no HUCFF.

\section{AGRADECIMENTOS}

Gostaríamos de agradecer a todos os docentes, aos médicos e demais funcionários do corpo administrativo, assim como aos membros que compōem o Departamento de Radiologia da Faculdade de Medicina da Universidade Federal do Rio de Janeiro, do Hospital Universitário Clementino Fraga Filho e sua Pós-graduação, que direta e indiretamente cooperaram com o andamento desse trabalho.

Essa pesquisa também contou com o apoio da CAPES.

\section{REFERÊNCIAS BIBLIOGRÁFICAS}

1. Koch HA. A radiologia nos cursos de graduação cm medicina: Uma contribuição ao processo ensino-aprendizagem. Tese de Doutorado. Faculdade de Medicina, UFRJ, 1987.

2. Tonomura E. O ensino de Radiologia na formação do médico geral: a experiência da Universidade Federal do Rio de Janeiro. Dissertação de Mestrado, Faculdade de Medicina, UFRJ, 1989.

3. Pascoal MM. O ensino da Radiologia no programa curricular interdepartamental (PC) Medicina Clínica I e II: UFRJ. Dissertação de Mestrado, Faculdade de Medicina, UFRJ, 1992.

4. Paschoal MM. Proposta e uma metodologia de ensinoaprendizagem da Radiologia na graduação em medicina. Tese de Doutorado. Faculdade de Medicina da UFRJ, 2003.

5. Skinner BF. Tecnologia do Ensino. SP. Ed Universidade de São Paulo,1972.

6. Koch HA, Ribeiro ECO, Tonomura ET. A Radiologia na formação do Médico Geral. Rio de Janeiro. Revinter, 1997.

7. Geraldeli FE. Produção de material instrucional para o ensino da Radiologia através da digitalização de imagens. Dissertação de Mestrado. Faculdade de Medicina da UFRJ, 2001.

8. Silva AA. Tradução computacional dos achados vídeofluoroscópios da dinâmica da fase oral $c$ faríngea da deglutição: imagens anatômicas básicas. Dissertação de Mestrado. Faculdade de Medicina da UFRJ, 2001.

9. Batista NA, Silva SHSW. O professor das escolas médicas brasileiras: uma aproximação. In: O professor de Medicina. São Paulo. Ed. Loyola, 1998; 45-52.

10. Tardif M, Raymond D. Saberes, tempo e aprendizagem do trabalho no magistério. Educação e Sociedade, 2000; 209244.

11. Incontri D. A Educação da Nova Era. São Paulo, Editora Comenius, 2001.

12. Goldenberg M. A arte de pesquisar. Como fazer pesquisa qualitativa em Ciências Sociais. Rio de Janeiro. $3^{\text {ㄲ }}$ ed. Editora Record, 1995.

13. Schramm, FR. Contribuiçōes da Bioética e da Comunicação à Educação Médica. Rev Bras Educ Med. 2001; 25:15-24. 
14. Brasil. Ministério da Educação. Conselho Nacional de Educação. Resolução CNE/CES 04/2001. Diário Oficial da Uniāo. Brasília, 9 de novembro de 2001. Seção 1, p. 38.

15. Menezes M. O sentido do sofrimento, do desafio à superação. Uma visão transpessoal e espiritual do sentido do sofrimento na construção da felicidade. Editora Leymarie. Rio de Janeiro, 2002.

16. Osório LC. Psicologia Grupal: uma nova disciplina para o advento de uma era. Porto Alegre: Artmed, 2003.

\section{ANEXOI}

\section{Roteiro da Entrevista com o Docente}

(Abordagens de assuntos ligados ao seu cotidiano de trabalho )

1 - Trajetória de vida e aspirações do Docente.

a) Obstáculos que se apresentam na prática cotidiana.

b) Razões de opção pelo magistério.

c) Razões de opção pela pesquisa.

d) $\mathrm{O}$ que sente mais prazer em fazer entre ensino e pesquisa.

e) Sente orgulho por ser Médico / Docente da UFRJ.
2 - Condições de trabalho do Docente.

a) Questões de valorização do trabalho do Docente através da salário.

b) Problemas de relacionamentopessoal e inter-departamental.

c) Já sofreu algum tipo de discriminação.

d) Aulas em outra instituição.

\section{Endereço para correspondência}

Maria de Fátima do O' Corrêa Gomes

Rua Amapurus, 297, Bloco 3 / 204 - Ilha do Governador 21920-120 - Rio de Janeiro - RJ

e-mail: fatimado@uol.com.br

Evandro Guimarães de Sousa

Rua Coelho Neto, 520 - Tabajaras

38400-286 - Uberlândia - MG

e-mail: evansousa@hotmail.com.br

Hilton Augusto Koch

Rua Adalberto Ferreira, 46 / 502 - Leblon

22.440-041 - Rio de Janeiro - RJ

e-mail: hakoch@uol.com.br 